\title{
Combined satellite- and ULS-derived sea-ice flux in the Weddell Sea, Antarctica
}

\author{
Mark R. Drinkwater, ${ }^{1 *}$ Xiang Liv, ${ }^{1}$ Sabine Harms ${ }^{2 \dagger}$ \\ ${ }^{1}$ Jet Propulsion Laboratory, California Institute of Technology, 4800 Oak Grove Drive, Pasadena, CA 91109-8099, U.S.A. \\ ${ }^{2}$ Alfred-Wegener-Institut für Polar- und Meeresforschung, Postfach 120161, D-27515 Bremerhaven, Germany
}

\begin{abstract}
Several years of daily microwave satellite ice drift are combined with moored upward-looking sonar (ULS) ice drafts into an ice-volume flux record at points along a flux gate across the Weddell Sea, Antarctica. Monthly ice transport varies at the mooring locations from a maximum export of $0.4 \mathrm{~m}^{3} \mathrm{~s}^{-1}$ near Joinville Island to $-0.4 \mathrm{~m}^{3} \mathrm{~s}^{-1}$ imported along the Fimbul and Riiser-Larsen ice-shelf margins. Winter peaks are observed at each end of the flux gate, where high concentrations of deformed ice are advected in and out of the basin along the coastline. The central gyre, in contrast, exhibits negligible seasonality and much smaller volume transports. During the period of overlapping ULS operation, the mean monthly integrated ice export west of the gyre center is $59 \times 10^{3} \mathrm{~m}^{3} \mathrm{~s}^{-1}$, and the import in the East Wind Drift is $-17 \times 10^{3} \mathrm{~m}^{3} \mathrm{~s}^{-1}$. ULS data are compared with ERS satellite observation of radar backscatter to obtain an empirical relationship between ice thickness and the rate of change of backscatter with incidence angle. Resulting proxy ice-thickness data are combined with Special Sensor Microwave/Imager-derived ice velocities to obtain seasonally varying estimates of net ice-volume flux for the period 1992-98. Significant interannual variability is observed in ice-volume flux expressed as fresh-water transport. A maximum annual mean of $0.054 \mathrm{~Sv}$ is observed in 1992, with a minimum of $0.015 \mathrm{~Sv}$ in 1996. A 6 year mean transport of $0.032 \mathrm{~Sv}$ is observed. Maximum seasonal ice export occurs in July 1992, with a minimum in November 1996. The 10 year mean area flux is $30 \times 10^{3} \mathrm{~m}^{2} \mathrm{~s}^{-1}$. Interannual variations in net volume flux closely follow variations in area flux, with summer minima in 1990/91 and 1996/97. Maximum area transport occurs in 1991, and although this predates the ERS-1 scatterometer data, ice-thickness estimates by Harms and others confirm 1991 as a decadal peak in net integrated fresh-water transport.
\end{abstract}

\section{INTRODUCTION}

Antarctic sea-ice dynamics and thermodynamics regulate surface fluxes of heat, water and momentum between atmosphere and the Southern Ocean. Momentum and vorticity is transferred to the ice through kinematic stresses from surface winds. The resulting ice drift arises from a balance between wind stress and a combination of ocean-ice and internal ice stresses, and the Coriolis force. In the Weddell Sea, the circulation pattern comprises a clockwise gyre (Deacon, 1979). The sea-ice circulation pattern is established by long-term mean synoptic low pressure centered over the eastern Weddell Sea with additional periodic impulses from passing storm systems (Kottmeier and Sellmann, 1996). Tides and currents provide additional forces, although with different frequencies and a less dominant impact on ice advection (Drinkwater, 1998b).

During the winter, ice drifts into the Weddell Sea along the northern margin of the Fimbul Ice Shelf in the East Wind Drift (EWD) coastal current. The Antarctic Peninsula impedes westward drift, and ice is compressed before being

\footnotetext{
* Present address: European Space Agency, ESTEC, Keplerlaan 1, P.O. Box 299, 2200 AG Noordwijk ZH, The Netherlands.

† Present address: Institut für Meereskunde, Abt. Meeresphysik, Duesternbrooker Weg 20, D-24105 Kiel, Germany.
}

forced northwards out into the swift-moving eastward Antarctic Circumpolar Current (ACG). The Weddell gyre thus provides a conveyor belt along which fresh water (in the form of ice) and small quantities of brine are transported and redistributed. Continuous ice removal from the southern Weddell Sea results in large polynyas opening along the northern margin of the Filchner-Ronne Ice Shelf. New-ice growth rapidly replaces ice that is advected northwards, yielding enhanced freezing rates over continental-shelf regions. Brine rejected during the freezing process contributes to the salination and nourishment of high-salinity shelf water (Carmack, 1986), driving the formation of dense, "deep" and "bottom water" as it sinks and mixes downslope from the continental-shelf break (Warren, 1981).

Our knowledge of the Weddell ice-drift dynamics is derived from a combination of historical drifting-buoy deployments since the early 1980s (for detailed reviews see Kottmeier and Sellmann, 1996; Vihma and others, 1996), a drifting ice camp in 1992 (Gordon and others, 1993) and assorted model simulations (Lemke and others, 1990; Geiger and others, 1998; Harder and Fischer, 1999). The number of simultaneously reporting buoys in the Weddell Sea has been limited to less than 11, with the maximum of 10 in 1992. Most years are characterized by relatively sparsely distributed satellite-buoy trajectories, preventing a comprehensive picture of the spatial or seasonal-to-interannual variability in ice drift from being established. Early Weddell Sea ice-transport estimates were made by Limbert and others (1989) and Vihma and others 


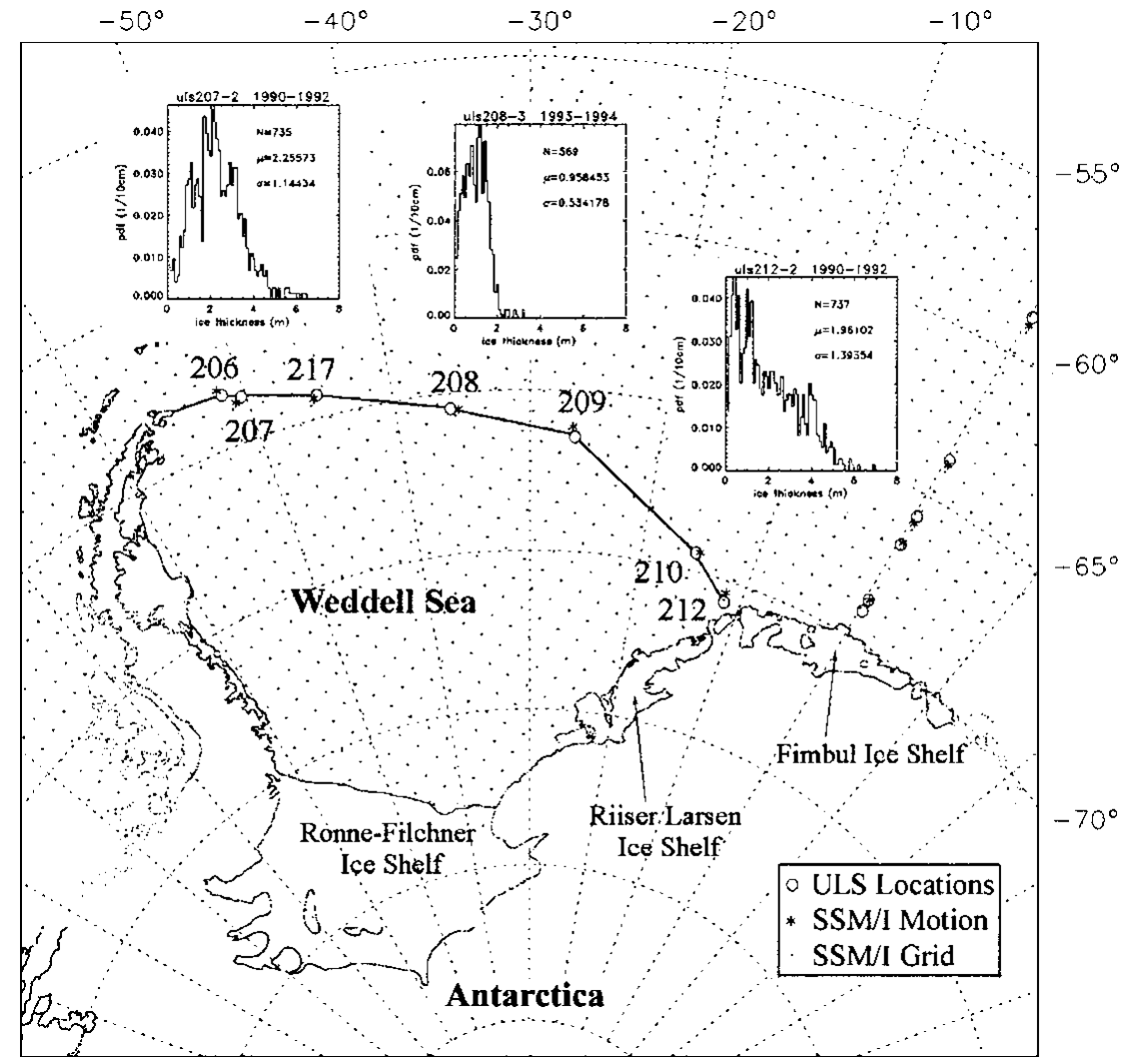

Fig. 1. Map of Weddell Sea moorings deployed by the AWI and the flux gate (solid line) across which ice area and volume fluxes are computed. Insets show ice-thickness probability distributions from 207-2, 208-3 and 212-2 during the periods indicated. Gridpoints indicate locations of Eulerian SSM/I drift, and stars indicate gridpoints from which ice-drift velocities are combined with ULS mooring data. Moorings along the Greenwich meridian are not discussed in this paper.

(1996) on the basis of extremely sparse buoy measurements and an empirical relationship between geostrophic wind and ice drift. Each suffers from inaccuracies in the assumed spatial variability of sea-ice thickness and the assumption that ice drift conforms to the linear Thorndike and Colony (1982) model. Model simulations of Weddell Sea ice drift, on the other hand, can be tuned to appear consistent with buoy trajectories (Drinkwater and others, 1995; Harder and Fischer, 1999). The resultant ice-thickness distributions have not, however, been rigorously validated against ULS ice-thickness data.

Recently, Harms and others (2001) have combined timeseries ice-thickness measurements from several upwardlooking sonars (ULSs) with buoy-drift results from Kottmeier and Sellmann (1996) to provide the most detailed picture of time--space variability in ice transport to date. A simple but effective empirical relationship is developed between length of ice season and ULS volume transport. Although this relationship is successfully employed to calculate the interannual variability in the integrated net ice transport, the accuracy of their estimates is limited by the dependence upon an empirical wind-drift factor. Importantly, these data also do not allow seasonal variability in net transport to be calculated.

New Antarctic satellite ice-drift data permit direct icetransport and -export calculations when combined with direct ice-thickness measurements. In this paper, we take Harms and others' (2001) results a step further towards compiling comprehensive satellite-derived, seasonally varying icetransport estimates in the Southern Ocean. To accomplish this, we first combine daily satellite measurements of ice drift with daily ULS thickness records to obtain volume transport at each ULS mooring location. A new empirical relationship is then developed between measured ice-thickness and satellite microwave radar image data such that a proxy record of time--space variability in ice thickness can be combined with satellite-derived ice-drift maps. These data are used to calculate monthly mean ice-volume flux across a flux gate linking each ULS mooring location over the period 1992-98.

\section{DATASETS}

\section{ULS ice-thickness measurements}

ULS instruments were deployed by the Alfred Wegener Institute (AWI) on 12 bottom moorings spanning the Weddell Sea using the ice-breaker R.V. Polarstern (Strass and Fahrbach, 1998). Figure 1 indicates the locations of each of the moorings together with the conceptual "flux gate" used in our calculations. Mooring sites were chosen to measure the time-varying inflow and outflow of ice in the Weddell gyre. Combined data from multiple mooring deployments span the period 1990-98, although there is no period when ULS operated simultaneously on all moorings. Harms and others (2001) describe in further detail all measurement periods for each of the ULS moorings as well as the redeployments.

Each operable ULS instrument recorded the time-varying sea-ice draft $d_{\mathrm{i}}$ at $8 \mathrm{~min}$ intervals over deployment periods of 1-2 years. ULS draft measurement data supplied by the AWI were already binned in two different ranges $(0-10 \mathrm{~m}$; and all drafts). Data binned in the cut-off range $0-10 \mathrm{~m}$ are used by Harms and others (2001) to assess relative iceberg bias to ice-thickness distribution. Both datasets were ensembleaveraged over $24 \mathrm{~h}$ and monthly intervals, and ice draft converted to thickness $H_{\mathrm{i}}$ using $\bar{H}_{\mathrm{i}}=0.028+1.012\left\langle d_{\mathrm{i}}\right\rangle$ after 
Harms and others (2001). This draft-to-thickness relationship was established from ice-core drillings in the Weddell Sea (Wadhams and others, 1987; Lange and Eicken, 1991; Eicken and others, 1994).

\section{Ice-motion and concentration data}

Historical Antarctic buoy-array data are sparse, in contrast to data for the Arctic basin, and therefore a Southern Oceanwide satellite-derived ice-motion dataset is a primary prerequisite for understanding the response of Southern Ocean sea-ice cover to meteorological and oceanographic forcing. Daily, gridded Special Sensor Microwave/Imager (SSM/I) ice-motion data for this study were supplied by C. Fowler and J. Maslanik of the University of Colorado. Ice-drift data are generated by tracking features in sequential pairs of $\mathrm{SSM} / \mathrm{I} 85 \mathrm{GHz}$ radiometric images ( $\sim 14 \mathrm{~km}$ resolution) using the maximum cross-correlation technique (Emery and others, 1997). Resulting drift data were projected on a polar stereographic grid to facilitate overlaying vectors onto other satellite remote-sensing products. The ice displacements and velocities were gap-filled by interpolation and then gridded at $\sim 90 \mathrm{~km}$ intervals for the period 1987-98. Antarctic ice-motion results have previously been reported by Emery and others (1997), Kwok and others (1998) and Stammerjohn and others (1998), and the comparative details of each of these ice-motion products are reviewed in detail by Maslanik and others (1998).

Comparisons of Weddell Sea ice-drift vectors with daily buoy-drift data indicate root mean square (rms) errors for $x$ and $y$ daily displacements of about $7.0 \mathrm{~km}$. This corresponds with $1 \mathrm{~d} \mathrm{rms}$ drift-speed errors of $\sim 8 \mathrm{~cm} \mathrm{~s}^{-1}$. Although rms errors are clearly at the SSM/I sub-pixel scale, as Kwok and others (1998) point out, daily ice-motion estimates are noisy. Since comparisons with buoy data indicate Gaussian distributed errors and zero mean bias, monthly averaging was performed to reduce ice-tracking errors. Comparisons of averaged motion fields with buoy motions indicate that the standard error decreases in proportion to $1 / \sqrt{n}$. The standard error for estimating monthly mean velocities is therefore $1.45 \mathrm{~cm} \mathrm{~s}^{-1}$ or around $18 \%$.

$\mathrm{SSM} /$ I gridded measurements of ice motion are supplemented by NASA-team algorithm ice concentrations (Gloersen and others, 1992) at a pixel spacing of $25 \mathrm{~km}$. Contiguous regions of the ice pack with ice concentration exceeding $15 \%$ are applied as a common time-space mask for all datasets. Notably, NASAteam concentrations do not correspond precisely with the period of ice coverage estimated from the ULS data. This artificially shortens the period of the year when valid ice-volume flux calculations can be made. Nevertheless, this methodology removes problematic periods when adverse weather conditions or wet summer ice surfaces can cause problems to the ice tracker or may result in spurious flux estimates.

\section{ERS scatterometer images}

Antarctic ERS-1 and ERS-2 C-band $(5.3 \mathrm{GHz})$ wind scatterometer (EScat) swath data were processed to images using the algorithm described in Drinkwater and others (1993). EScat data processing yields $A$ and $B$ image products that describe the mean microwave backscatter of the surface over a $6 \mathrm{~d}$ imaging period (Drinkwater, 1998a, b). Pixel values in $A$ images are normalized backscatter coefficient at $40^{\circ}$ incidence. $B$ values indicate the linear rate of decay of backscattering across the full-swath incidence-angle range $20-60^{\circ}$. Specific

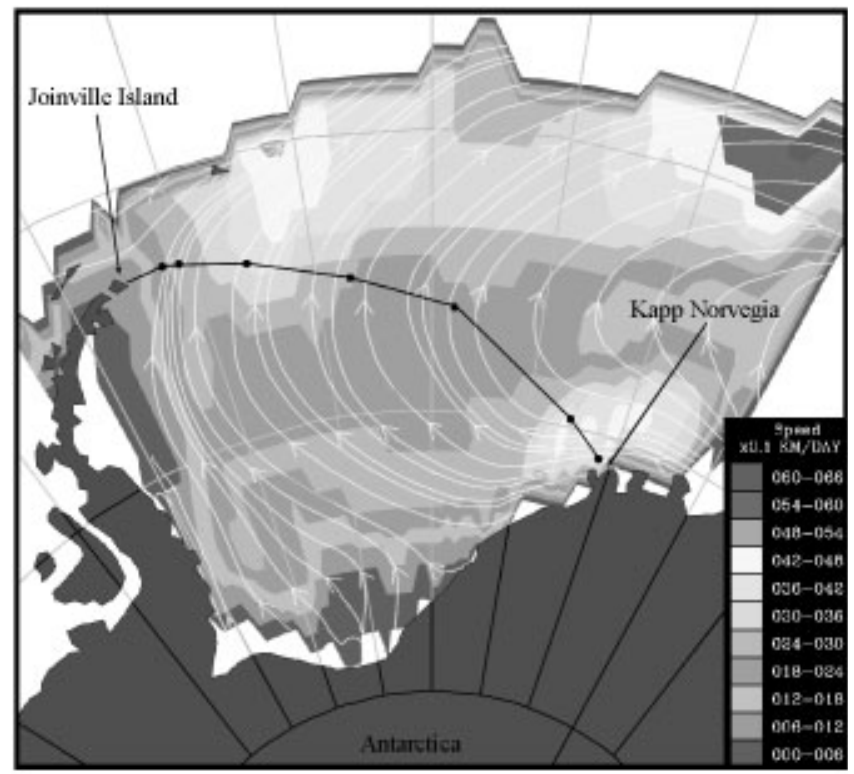

Fig. 2. Weddell Sea 1994 daily mean SSM/I-tracked ice-drift streamlines, and spatial variability in drift speed. ULS mooring locations are indicated.

characteristics of EScat images are described in further detail by Drinkwater (1998a, b); and Long and Drinkwater (1999) illustrate applications of SIRF scatterometer images to the study of polar ice.

EScat backscatter images were generated at $3 \mathrm{~d}$ intervals and have an improved resolution exceeding $25 \mathrm{~km}$ (Long and others, 1993). Images are gridded with a pixel spacing of $\sim 9 \mathrm{~km}$ and projected onto the same polar stereographic grid as the SSM/I data. EScat images were averaged over monthly intervals for comparison with monthly mean ULS thickness estimates. In the following sections we focus on the period of overlap between SSM/I and EScat from 1992 until 1998.

\section{SATELLITE ICE DRIFT}

Time-varying Eulerian ice velocity $V_{\mathrm{i}}(t)$ was extracted from the gridded SSM/I motion data at each of the ULS locations and combined with the corresponding ice thickness $H_{\mathrm{i}}(t)$ to compute variations in ice-volume transport. Monthly averaging was performed on both daily datasets prior to the multiplication.

Figure 2 indicates 1994 annual mean daily drift. The colour legend indicates drift speed, and the white streamlines indicate typical trajectories of sea-ice floes in the Weddell gyre. Converging and diverging streamlines intuitively imply ice convergence and divergence. The pattern indicates relatively rapid inflow at Kapp Norvegia focused between ULS 210 and 212, with drift speeds reaching $5 \mathrm{~km} \mathrm{~d}^{-1}$. Inflowing ice decelerates in the central gyre at its confluence with ice formed along the margin of the Filchner-Ronne Ice Shelves. It is compressed against the coast of the Antarctic Peninsula and forced northwards. Ice drifts parallel to the Peninsula before accelerating and turning northeastwards as it passes Joinville Island and becomes entrained in the ACC. The highest drift speeds are observed in the marginal ice zone, where winds and currents combine to drive the ice at $>6 \mathrm{~km} \mathrm{~d}^{-1}$. Zones of relatively slower ice drift are observed particularly in the coastal southern and western Weddell Sea due to transfer of internal ice stresses over distances of a few hundred kilometers from the shore. 

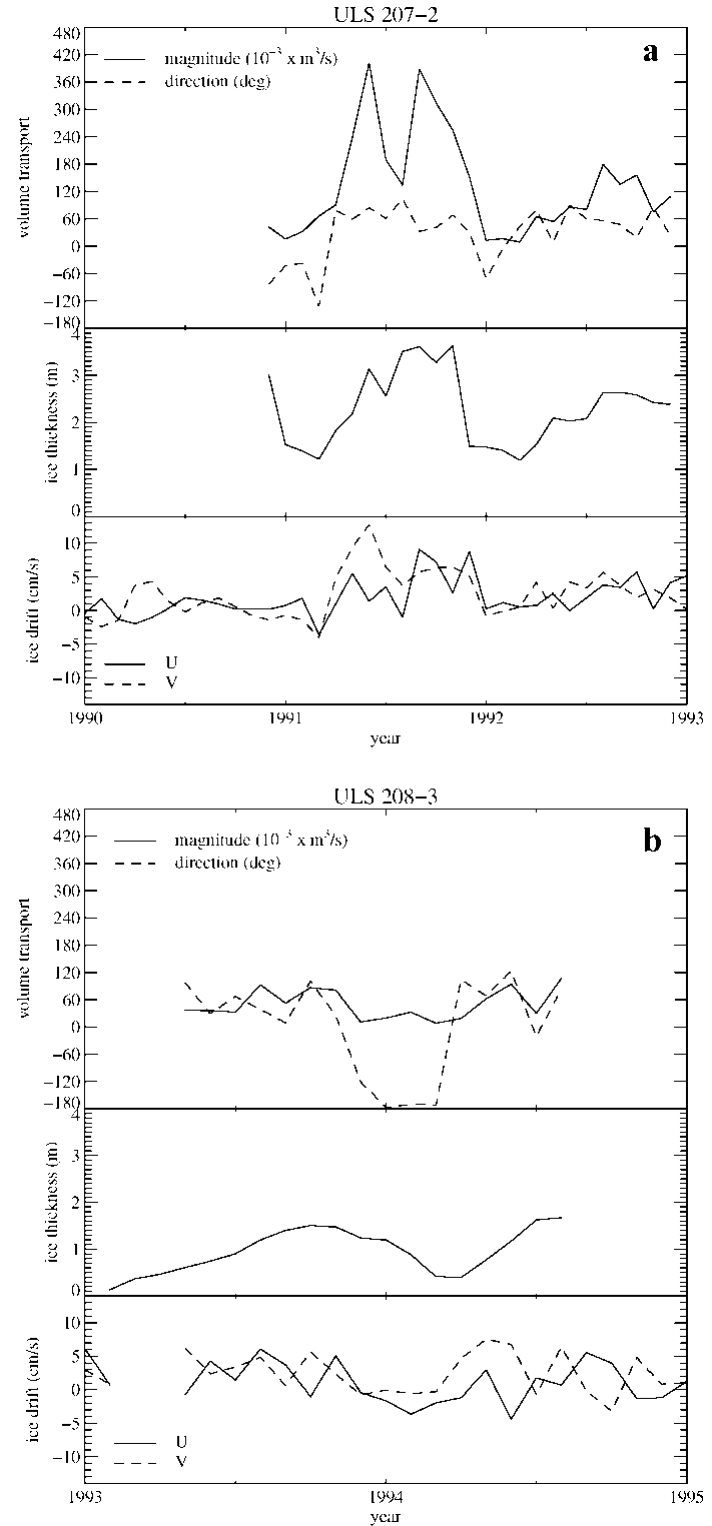

Fig. 3. Time series at ULS moorings ( a) 207 and (b) 208 of monthly mean ice-volume transport (upper panel), derived from combinations of ULS ice thickness (middle panel) and SSM/I tracked ice-drift speed (lower panel).

\section{ULS VOLUME TRANSPORT}

Figure 1 insets show ice-thickness probability distribution functions (PDFs) at three of seven ULSs along the Weddell flux gate. Statistics are provided for the total number of daily mean values together with the overall mean and standard deviation of ice thickness during the given period of ULS operation. As reported by Strass and Fahrbach (1998), PDFs in the interior region reflect the maximum attainable thermodynamic growth thickness in a predominantly divergent ice pack. The ULS 208 PDF (Fig. 1) reports a mean thickness of $0.96 \mathrm{~m}$ and negligible fractions of ridged ice. In contrast, ULSs 207-2 and 212-2 report large fractions of deformed ice caused by dynamical processes such as ridging of thin ice forming in leads and polynyas. Drinkwater and Haas (1994) report in situ ice-thickness data along a similar flux gate during 1992 Winter Weddell Gyre Study (WWGS'92). These data indicate the same general ice characteristics across the gyre. ULS 212-2 reports particularly deformed ice in the vicinity of Kapp Norvegia, consistent with helicopter-borne laser-altimeter measurements of highly rubbled and ridged ice (Dierking, 1995), and the Polarstern be-

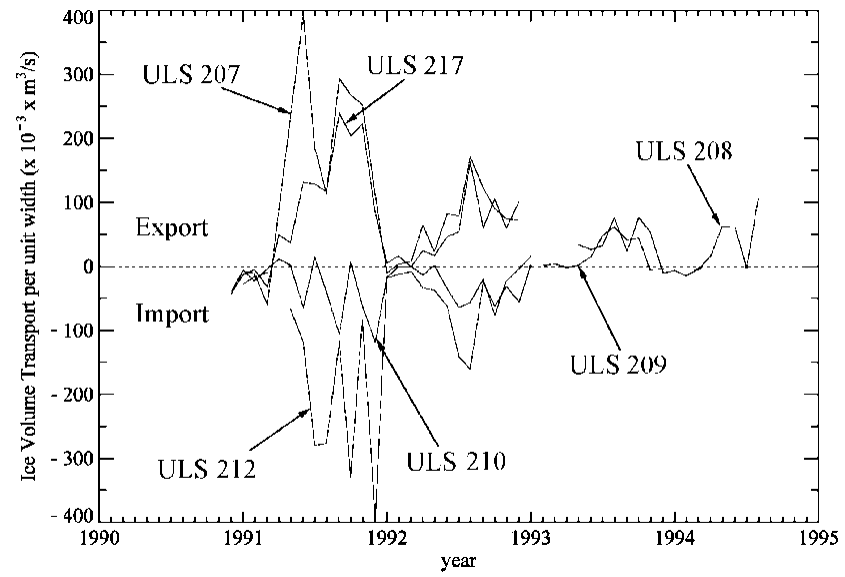

Fig. 4. Seasonal variability in ice-volume transport at ULS moorings.

coming beset in compressed ice in that location in 1992 (Lemke, 1994). As ice circulates around the Weddell Sea, thin ice grown in leads openings during wind-driven or tidal ice divergence becomes rafted and ridged. The increase in the mode from 0.2 to $2.0 \mathrm{~m}$, together with the increase in mean ice thickness between the locations of ULS moorings 212-2 and 207-2 (Fig. 1), is attributed to the redistribution of thin ice into the thicker part of the distribution.

Mean satellite-tracked ice-drift velocities are combined with mean ULS thickness at monthly intervals in Figure 3 to compute volume transport of sea ice. The bottom panel shows the local $u$ and $v$ components of ice velocity $\left\langle V_{\mathrm{i}}\right\rangle$, and the middle panel shows monthly scalar mean ULS thickness measurements $\left\langle H_{\mathrm{i}}\right\rangle$. The upper panel indicates time-varying volume transport $\Phi$, where $\Phi=\left\langle V_{\mathrm{i}}\right\rangle \times\left\langle H_{\mathrm{i}}\right\rangle$.

Results from ULSs 207-2 and 208-3 indicate an icevolume flux toward the northeast out of the Weddell Sea throughout the winter months, with a local direction which fluctuates around a mean of $\sim 60^{\circ}$ (positive $=$ clockwise). Summer reversals in flux direction occur periodically at most ULS locations with southwesterly motion noted in February 1992 at ULS 207 (Fig. 3a), and a more extended period of south-southwesterly ice recession at ULS 208 (Fig. 3b) from January to March 1994. Strong seasonal cycles in velocity and ice thickness near toJoinville Island (ULSs 206, 207 and 217) lead to correspondingly large seasonal variations in volume transport between 0 and $0.42 \mathrm{~m}^{3} \mathrm{~s}^{-1}$. In contrast, the central gyre exhibits a much smaller range of seasonal variability marked by a relatively gradual increase in ice thickness over the ice-growth season. The smaller mean and variance in ice thickness and velocity in the interior lead to volume transports in the range $0-0.12 \mathrm{~m}^{3} \mathrm{~s}^{-1}$ at mooring 208.

Figure 4 shows a comparison of seasonally varying ULS volume transport during the period of greatest overlap in ULS operation. Relative transport is computed in fixed directions of $225^{\circ}$ and $17^{\circ}$ for net drift into and out of the Weddell Sea, respectively. Flux magnitudes are roughly equivalent at the eastern and western extremes of the flux gate, although ice is imported along a relatively narrow portion of the eastern end of the flux gate between ULSs 210 and 212 in Figure 2. Seasonal variations in the time series of export at ULSs 207 and 217 are mirrored cycles at locations 212 and 210, suggesting that advection and ice transport in the Weddell gyre speeds up and slows down during the winter and spring months.

Significant differences between fluxes computed at ULSs 


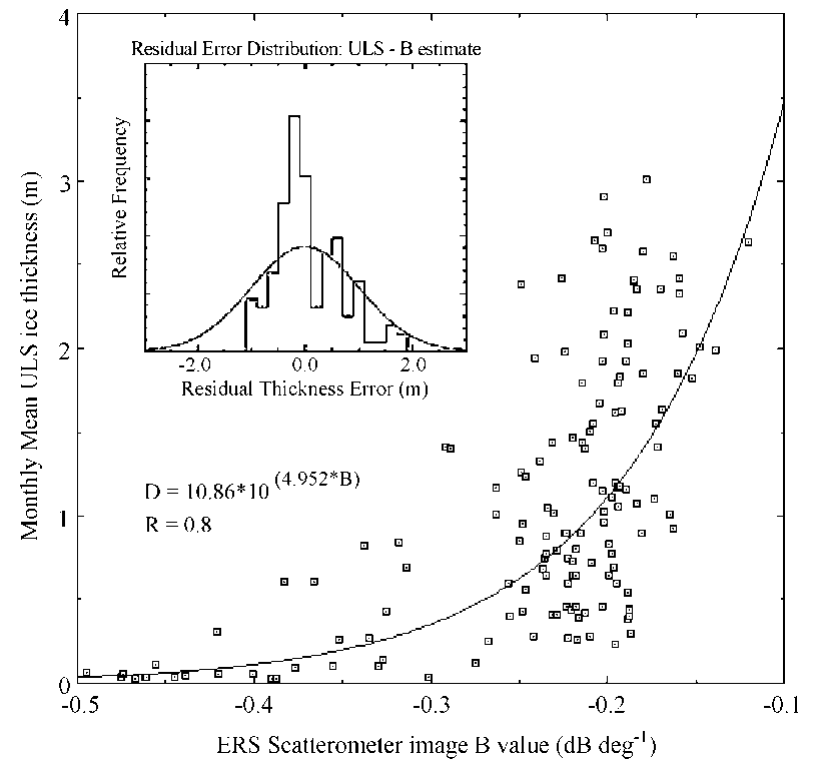

Fig. 5. Empirical relationship between Weddell Sea monthly mean ULS ice thickness and ERS scatterometer B image pixel values. The curve indicates the exponential relationship Equation (1) fitted to the data. The inset shows the histogram of the residual errors (ULS predicted value) and its comparison with a zero mean Gaussian error distribution.

212 and 210 (in Fig. 4) indicate the strong decay in volume fluxes with distance from the coast noted by Strass and Fahrbach (1998) at Kapp Norvegia. Furthermore, this difference reiterates that satellite-derived ice-motion datasets and models must effectively resolve strong coastal ice fluxes around the Antarctic coast for the fresh-water balance to be correctly computed. Significant discrepancies are noted at the western end of the flux gate, between the results of Harms and others (2001) and our findings. The simple linear drift model they employed does not successfully account for the spatial gradient in ice velocity between ULS 207 and Joinville Island, and as a consequence they overestimate the ice-volume flux at mooring 206.

\section{PROXY ICE-THICKNESS RECORD}

Without simultaneous overlapping annual cycles at each of the mooring locations it is impossible to integrate volume transport across the Weddell Sea. Harms and others (2001) find an empirical relationship between annual volumetransport ice and the length of ice season, determined from independent SSM/I ice concentrations. Although this provides a record of interannual variations in volume transport, it does not tell us about the significant seasonal variations clearly apparent in the individual monthly records in Figures 3 and 4. This prompted further efforts to find an empirical relationship allowing monthly mean transports to be calculated along the entire flux gate.

\section{Empirical relationship}

Figure 5 shows a scatter plot derived from comparisons of monthly mean $B$ pixel values in EScat images with monthly mean ice thickness at each mooring. The scatter indicates a
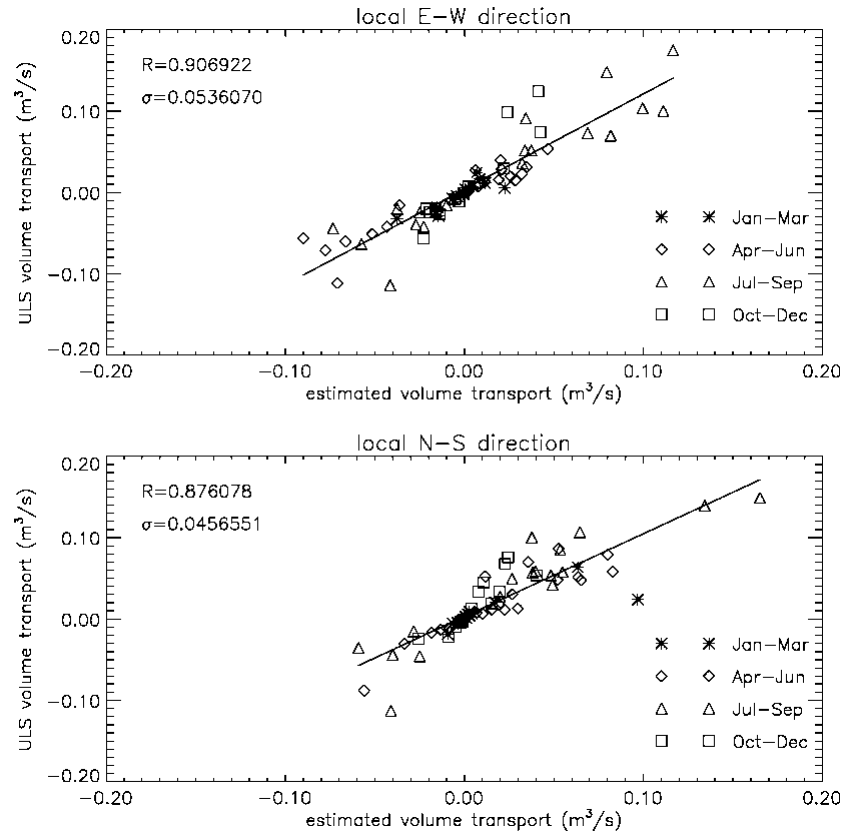

Fig. 6. Comparison of monthly mean estimates of volume transport at each ULS mooring for ice-covered months with SSM/I ice drift, ULS ice-thickness data and EScat estimates of ice thickness.

logarithmic relationship between $B$ and $\left\langle H_{\mathrm{i}}\right\rangle$. The following curve was fitted to the data using least-squares regression:

$$
\hat{D}_{\mathrm{i}}=10.86 \times 10^{4.95 B} \text {, }
$$

where $B$ is the monthly mean gradient in radar scattering coefficient at the ULS location. A correlation coefficient of $R=0.8$ suggests that $\sim 65 \%$ of the year-round variance in ice thickness can be explained by the temporal and spatial variability in C-band scatterometer image data. The rougher the ice surface becomes, the less rapidly radar backscatter decays with increasing incidence angle.

An alternative piecewise linear relationship was tested, which requires a priori distinction between deformed and undeformed ice regimes during different seasonal periods. With limited amounts of monthly ULS data available, this strategy is presently difficult to test or validate. Furthermore, since sufficiently reliable ice-classification data are not available for the entire period of interest, this alternative approach was discarded in favour of a more simple one-parameter fit. Future ULS data collection will allow seasonal and spatially varying relationships to be developed.

\section{Thickness-estimate error analysis}

Thickness-estimate error is computed as the difference between monthly mean ULS ice thickness and EScat-predicted ice thickness, as $\left\langle H_{\mathrm{i}}\right\rangle-\hat{D}_{\mathrm{i}}$. The inset in Figure 5 shows the histogram distribution of these errors in comparison with a Gaussian distribution. The mean error is close to zero, and the standard error in estimating mean ice thickness is $61 \mathrm{~cm}$. This estimate error is large in comparison with the standard deviation of ice thickness $\sigma_{H_{\mathrm{i}}}$ (Fig. 1) or the typical standard measurement error of the monthly mean ULS thickness, defined as $\sigma_{H_{\mathrm{i}}} / \sqrt{N}$. Typically, $\sim 5000$ independent ULS thickness samples are taken during a 1 month interval. For a typical mean ice thickness of $0-2 \mathrm{~m}$, this translates into a standard ULS measurement error of $\pm 0.03 \mathrm{~m}$. Though the $61 \mathrm{~cm}$ standard error in making estimates from EScat $B$ 
images is relatively large, it represents only $20 \%$ of the range of typical monthly mean thickness values $(0-3 \mathrm{~m}$ in Fig. 1$)$.

Figure 6 shows a comparison between estimated volume transport, calculated using Equation (1) and SSM/I ice motion, and ULS volume transport $\Phi$ described in the previous section. Monthly mean data points are broken down by season to indicate whether seasonal ice conditions impact ice-thickness estimation accuracy. Indeed, there is no apparent seasonal bias in transport estimates in either directional component. The standard deviation in volume-transport estimates using EScat-derived proxy thickness and SSM/I ice motion is therefore $0.05 \mathrm{~m}^{3} \mathrm{~s}^{-1}$.

In general, the empirical relationship has its greatest sensitivity at the thin end of the thickness distribution, and the ERS scatterometer is capable of delineating areas of smooth and deformed young ice. Equation (1) slightly underestimates the thickness of perennial and deformed ice. Regional and seasonal partitioning of data points in Figure 5 demonstrate this is due to winter confusion between volume- and rough-surface-scattering ice-floe surfaces, and the fact that undeformed perennial ice with a deep snow cover can produce a scattering signature similar to that of extremely deformed first-year ice. Summer melting, in contrast, reduces such problems in thickness estimation from $B$ images, as it exaggerates the scattering contrast between ridged/rubbled and level ice surfaces. Wet snow and ice surfaces reduce penetration, thereby limiting confusing volume-scattering effects from internal inhomogeneities within the snow and ice.

\section{INTEGRATED VOLUME FLUX}

Initially we computed annual net ice-volume flux orthogonal to the flux gate by (i) finite-differencing ULS measured monthly mean $\Phi$ values in Figure 4 (between moorings); (ii) performing a time integral on the resulting monthly flux to obtain annual integrated ice-flux values; and (iii) summing integrated fluxes across all line segments along the flux gate. Results are also compared with those obtained by linearly interpolating to $1 \mathrm{~m}$ intervals along the flux gate (as performed by Harms and others (2001)), but the results did not differ significantly nor warrant the additional computational burden of interpolation.

Our finite-difference results were compared with those of Harms and others (2001) in order to assess the improvement when satellite-tracked drift is incorporated in calculations of net volume flux. Their estimates rely upon a combination of the linear ice-drift model of Thorndike and Colony (driven by European Centre for Medium-range Weather Forecasts winds) with the same ULS thickness data. Relatively, their results suggest significantly exaggerated net ice export and import into the Weddell Sea at moorings 206 and 212, perhaps due to strong seasonal and spatial variability in internal ice strength not captured by the simple advective model. Overall, we obtain a $20 \%$ smaller integrated volume transport of $64 \times 10^{3} \mathrm{~m}^{3} \mathrm{~s}^{-1}$ for the western outflow and a $50 \%$ smaller influx of $18 \times 10^{3} \mathrm{~m}^{3} \mathrm{~s}^{-1}$ across the narrow eastern coastal inflow. Our net ice-flux budget orthogonal to the flux gate is therefore $46 \times 10^{3} \mathrm{~m}^{3} \mathrm{~s}^{-1}$. Since net ice flux from the Weddell Sea was computed by subtracting inflow from the outflow, it appears that the significantly larger Harms and others net transport values partially cancel out one another. The result is that their overall net integrated volume transport is only around $10 \%$ greater than our value.

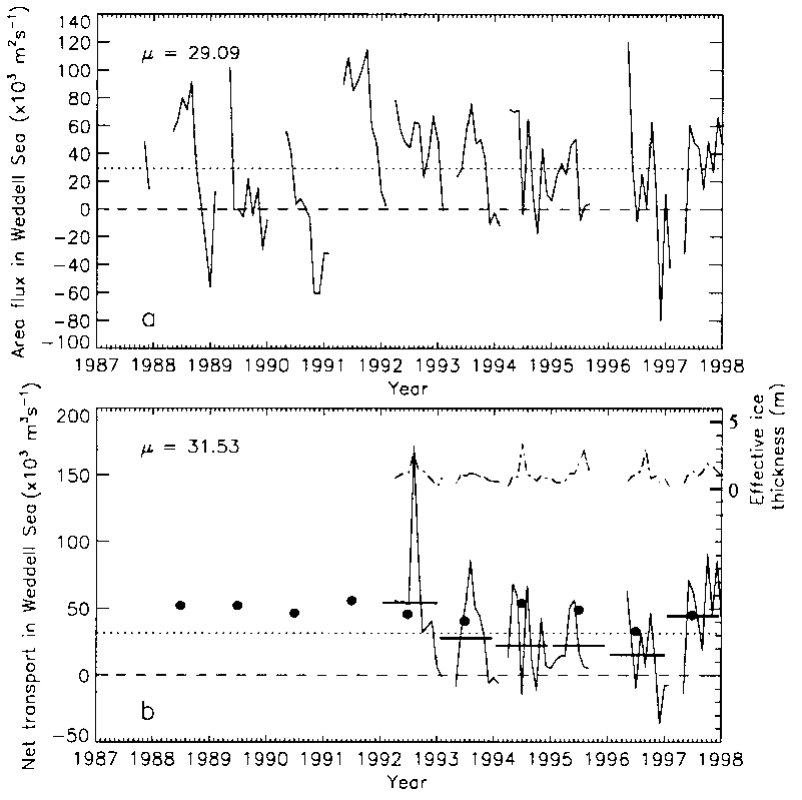

Fig. 7. Weddell Sea monthly mean values of $(a)$ net area flux and (b) net volume flux. Horizontal bars in (b) indicate annual means from this study, and solid circles indicate the annual means of Harms and others (2001). The dashed line in (b) shows the effective ice-thickness multiplier.

Comparisons were also made with the results of using the $10 \mathrm{~m}$ ice-thickness cut-off statistics described in section 2. A significant decrease is noted in the east-west component in volume flux at ULS 206 when the $10 \mathrm{~m}$ cut-off is used for its 1996-97 operating period. This suggests that the iceberg flux from the disintegrating Larsen Ice Shelf (Rott and others, 1998) may have significantly biased ice-thickness statistics at this mooring location. In general, however, use of a $10 \mathrm{~m}$ ice-thickness cut-off reduces volume flux by only a few per cent, due to icebergs having limited impact over most of the flux gate.

\section{ANNUAL IGE-VOLUME FLUXES}

Since the AWI ULS did not operate simultaneously along the Weddell flux gate, proxy EScat ice-thickness data (from section 5) are required to calculate seasonal and interannual variability in Weddell Sea net ice-volume flux. Monthly mean results in Figure 7 indicate the seasonal and interannual variability in net area and volume flux for periods when the flux gate is covered by ice exceeding $15 \%$ concentration. Figure 7 a shows a 9 year mean ice-area flux of $29 \times 10^{3} \mathrm{~m}^{2} \mathrm{~s}^{-1}$ from SSM/I ice-drift data (shown as dotted line). Monthly mean thickness estimates from Equation (1) are combined with the area flux to obtain the 6 year mean volume flux of $32 \times 10^{3} \mathrm{~m}^{3} \mathrm{~s}^{-1}$ (limited to the 1992-98 operation of ERS-1 and -2 ). This translates to an effective net mean fresh-water export of $32 \times 10^{3} \mathrm{~m}^{3} \mathrm{~s}^{-1}$ or $0.032 \mathrm{~Sv}\left(1 \mathrm{~Sv}=1 \times 10^{6} \mathrm{~m}^{3} \mathrm{~s}^{-1}\right)$. To assess errors in computing net fluxes we considered the standard estimation errors for ice drift and thickness in section 2, together with the $1 \sigma$ error bound of $0.05 \mathrm{~m}^{3} \mathrm{~s}^{-1}$ in transport in Figure 6 . We obtain errors in integrated net volume flux of about $25 \%$ of the mean monthly flux, and of the order of $5 \times 10^{3} \mathrm{~m}^{3} \mathrm{~s}^{-1}$ for the annual means shown in Table 1 .

\section{Seasonal to interannual variability}

Upper and lower panels in Figure 7 indicate the relative contributions of ice motion and thickness to net monthly 
Table 1. Weddell Sea annual mean fluxes of ice area and volume from combined SSM/I ice-drift velocities and EScat ice-thickness estimates

\begin{tabular}{|c|c|c|c|c|c|c|c|c|c|c|c|c|}
\hline Year & 1987 & 1988 & 1989 & 1990 & 1991 & 1992 & 1993 & 1994 & 1995 & 1996 & 1997 & Mean \\
\hline Net area flux $\left(10^{3} \mathrm{~m}^{2} \mathrm{~s}^{-1}\right)$ & 31.2 & 34.6 & 10.3 & -5.7 & 67.9 & 48.4 & 30.2 & 28.7 & 21.9 & 19.1 & 27.8 & $29 \pm 41$ \\
\hline ( $N$ months) & $(2)$ & (9) & $(10)$ & (9) & $(10)$ & $(11)$ & $(10)$ & $(11)$ & (8) & (9) & $(10)$ & \\
\hline Net volume flux $\left(10^{3} \mathrm{~m}^{3} \mathrm{~s}^{-1}\right)$ & - & - & - & - & - & 54.2 & 27.4 & 22.1 & 22.1 & 14.9 & 43.7 & $32 \pm 36$ \\
\hline Volume flux std dev. $(1 \sigma)$ & - & - & - & - & - & 45.9 & 31.4 & 31.4 & 20.1 & 31.2 & 35.9 & \\
\hline ( $N$ months) & - & - & - & - & - & $(10)$ & $(11)$ & $(10)$ & (8) & (9) & $(10)$ & \\
\hline Volume flux $\left(10^{3} \mathrm{~m}^{3} \mathrm{~s}^{-1}\right)$ (Harms and others, in press) & - & 52 & 52 & 46 & 56 & 46 & 41 & 54 & 49 & 33 & 45 & $46 \pm 7$ \\
\hline
\end{tabular}

variations in ice-volume transport. The absolute value of the ratio of the volume to area fluxes is also computed and added as a dashed line in Figure $7 \mathrm{~b}$. This quantity provides an indication of the seasonal variation in the mean "effective ice thickness".

Net transport typically increases rapidly from a summer minimum (when the least ice covers the basin) up to July peak values of $150 \times 10^{3} \mathrm{~m}^{3} \mathrm{~s}^{-1}$, as a consequence of large quantities of perennial ice floes advected out of the southwestern Weddell Sea (Drinkwater, 1998a, b). July-October values drop considerably in the western Weddell Sea as ice convergence retards ice drift and area flux. The most rapid ice-drift velocities are not normally observed in mid-winter, due to increased internal ice stress when the basin is completely filled by ice. Springtime area flux falls to seasonal minimum in all years except 1994 and 1997.

Table 1 shows the summary of annual mean values (based on monthly mean values in Fig. 7). It indicates that there is a significant interannual variability in both area and volume flux. The maximum area flux of $67.9 \times 10^{3} \mathrm{~m}^{2} \mathrm{~s}^{-1}$ occurs in 1991. Though these measurements predate our EScat data, ice-thickness estimates from Harms and others (2001) also confirm a 1991 decadal peak in net ice transport. The 1990 results, in contrast, indicate anomalously large net southward transport during the latter part of the year, reproduced only in the spring of 1988 and 1997.

Estimates of net ice export by Vihma and others (1996) using buoy-drift data show considerable differences with results in Table 1. The primary drawback noted in their work, however, is their lack of information on spatial and interannual variability in ice thickness. Their estimates are, as a result, biased low, with net ice-export values for 1992, 1993 and 1994 of 22,85 and $18 \times 10^{3} \mathrm{~m}^{3} \mathrm{~s}^{-1}$, respectively.

Further detailed comparisons of our annual means (horizontal bars) and those of Harms and others (2001), shown as solid circles, suggest that Harms and others slightly overestimate the long-term mean. This is perhaps not surprising given the tendency of the linear drift model to overestimate the advective component of the flux in situations with large internal ice stresses. More surprising, though, is the fact that our results capture significantly greater interannual variability in the net volume flux. This can only presently be explained by the extremely large seasonal variance demonstrated in this study, and the fact that their result does not capture the strong variations in the area flux.

A final comparison of our net ice-export result with the recent coupled-model predictions of Timmermann and others (2001) shows the long-term net mean volume transport estimate to be in close agreement with their simulated value of $0.034 \mathrm{~Sv}$. Their conclusions indicate that this fresh- water export is roughly balanced by basal melting of ice shelves $(\sim 0.09 \mathrm{~Sv})$ and net precipitation $(\sim 0.19 \mathrm{~Sv})$, with the remaining fresh water carried by the Weddell gyre.

\section{GONGLUSIONS}

Results in this paper are derived by applying an ice-volume transport integration strategy similar to that of Harms and others (2001). Our data indicate that strong spatial gradients in the area flux have a significant impact upon net icevolume flux, as do strong seasonal-to-interannual fluctuations in ice advection and thickness. Results demonstrate that it is vital to consider both spatial and temporal variability in ice drift in order to capture the true seasonal variance in sea-ice transport or fresh-water flux. It is particularly timely to exploit new gridded satellite-derived ice-drift datasets for this purpose.

As previous results have demonstrated, ice export is greatest at the north-western end of the flux gate (near the tip of the Antarctic Peninsula) and declines eastwards towards the central gyre. Ice import takes place in the coastal current entering at the east of the Weddell Sea across a narrow portion of the flux gate. Individual ULS moorings near Kapp Norvegia can indicate transports of comparable magnitude to those of ULS near the tip of the Antarctic Peninsula. Periods of significant volume import appear closely related to the amount of deformed ice entering along the coastal regime in the eastern Weddell Sea. The occurrence of large seasonal peaks in ice transport at ULS 212, for instance, appears to be related to strong ice-convergence events as reported by Lemke (1994). The net sea-ice budget of the Weddell Sea is, as a consequence, strongly modulated by the quantity of deformed ice carried into the basin along the Coats Land coast.

Direct flux estimates presented in section 7 should be treated with care. It was necessary to assume negligible interannual flux variability in order to combine non-overlapping ULS data from all moorings. We now know this not to be an appropriate assumption. An identical methodology to that of Harms and others (2001) was applied simply to make possible direct comparisons between net fluxes with and without satellite ice-drift data. ULS thickness data used in this integration were obtained from mixed periods between 1991 and 1997. Data from ULSs 207, 217 and 212 from the period 1991-92 (Fig. 4), in particular, indicate years and seasons with anomalously large transports. The resulting integrated net flux of $46 \times 10^{3} \mathrm{~m}^{3} \mathrm{~s}^{-1}$ is therefore biased high relative to the estimated 6 year mean of $32 \times 10^{3} \mathrm{~m}^{3} \mathrm{~s}^{-1}$.

Interannual variations in area and volume flux appear to indicate multi-year cycles characterized by positive and ne- 
gative anomalies with wavelengths of several years. This is not surprising given other supporting evidence for anomalies in sea-level pressure and large-scale atmospheric circulation patterns (Drinkwater, 1997). The time-scales associated with resulting patterns of fresh-water depletion and salt enrichment make it imperative that continued systematic, long-term in situ observations are made of ocean and ice properties in this region. This requires carefully designed deployments of moored sensors such as the AWI ULS data exploited in this study. The demonstrated relationship between ice-thickness and satellite data is undoubtedly limited by the highly variable regional and seasonal characteristics of Weddell Sea ice. Future calculations of net ice-volume flux will require continued seasonal-to-interannual measurements from such moored ULS sensors such that an accurate satellite-derived proxy record for ice thickness can be suitably developed. Only then can detailed satellite- derived ice-drift data and thickness estimates be fully exploited for Southern Oceanwide fresh-water and salt-balance calculations.

In future extensions of this work, we plan to compute fluxes using SSM/I gridpoint measurements of ice velocity at $100 \mathrm{~km}$ intervals along the flux gate, rather than finite-differencing between ULS mooring locations. This additional information on the spatial variability in ice drift and thickness will undoubtedly change the preliminary results shown here. Such data will allow much more accurate Weddell Sea budget estimates for salt and fresh water than could previously be made with sparsely deployed buoy arrays.

\section{ACKNOWLEDGEMENTS}

E. Fahrbach and V. Strass and the Alfred Wegener Institute are sincerely thanked for allowing access to these ULS data. M.D. and X.L. conducted this research at the Jet Propulsion Laboratory, California Institute of Technology, under contract to the National Aeronautics and Space Administration. Funding support was provided by NASA Code YS grant 622-82-31. ERS wind scatterometer data were provided by the European Space Agency and analyzed as part of European Space Agency project AO2.USA.119. Scatterometer images were produced in conjunction with D. Long of Brigham Young University as part of the Scatterometer Climate Record NASA Pathfinder Project.

\section{REFERENGES}

Carmack, E. C. 1986. Circulation and mixing in ice-covered waters. In Untersteiner, N., ed. Geophysics of sea ice. London, etc., Plenum Press, 641-712. (NATO ASI Series B: Physics 146.)

Deacon, G. 1979. The Weddell gyre. Deep-Sea Res., Ser. A, 26(9), 981-998.

Dierking, W. 1995. Laser profiling of the ice surface topography during the Winter Weddell Gyre Study 1992. 7. Geophys. Res., 100(C3), 4807-4820.

Drinkwater, M. R. 1997. Satellite microwave radar observations of climaterelated sea-ice anomalies. In Workshop on Polar Processes in Global Climate, 13-15 November, 1996, Cancun, Mexico. Proceedings. Boston, MA, American Meteorological Society, 115-118.

Drinkwater, M. R. 1998a. Active microwave remote sensing observations of Weddell Sea ice. In Jeffries, M. O., ed. Antarctic sea ice: physical processes, interactions and variability. Washington, DC, American Geophysical Union, 187-212. (Antarctic Research Series 74.)

Drinkwater, M. R. 1998b. Satellite microwave radar observations of Antarctic sea ice. In Tsatsoulis, C. and R. Kwok, eds. Analysis of SAR data of the polar oceans: recent advances. Berlin, etc., Springer-Verlag, 145-187.

Drinkwater, M. R. and C. Haas. 1994. Snow, sea-ice, and radar observations during ANT X/4: summary data report. Bremerhaven, Alfred Wegener Institute for Polar and Marine Research. Physics Department. (Report 53. )

Drinkwater, M. R., D. G. Long and D. S. Early. 1993. Enhanced-resolution ERS-1 scatterometer imaging of Southern-Ocean sea ice. ESA F., 17(4),
307-322.

Drinkwater, M. R., H. Fischer, M. Kreyscher and M. Harder. 1995. Comparison of seasonal sea-ice model results with satellite microwave data in the Weddell Sea. In IGARSS'95, Quantitative Remote Sensing for Science and Applications, Proceedings, 15th International Geoscience and Remote Sensing Symposium, 10-14 July 1995, Firenze (Florence), Italy. Vol. 1. New York, Institute of Electrical and Electronics Engineers, 357-359.

Eicken, H., M. A. Lange, H.-W. Hubberten and P. Wadhams. 1994. Characteristics and distribution patterns of snow and meteoric ice in the Weddell Sea and their contribution to the mass balance of sea ice. Annales Geophysicae, 12(1), 80-93.

Emery, W. J., C.W. Fowler and J. A. Maslanik. 1997. Satellite-derived maps of Arctic and Antarctic sea-ice motion. Geophys. Res. Lett., 24(8), 897-900.

Geiger, C. A., W. D. Hibler, III and S. F. Ackley. 1998. Large-scale sea ice drift and deformation: comparison between models and observations in the western Weddell Sea during 1992. F. Geophys. Res., 103(C10), 21,893-21,913.

Gloersen, P., W. J. Campbell, D. J. Cavalieri, J. C. Comiso, C. L. Parkinson and H. J. Zwally. 1992. Arctic and Antarctic sea ice, 1978-1987: satellite passivemicrowave observations and analysis. Washington, DC, National Aeronautics and Space Administration. (NASA SP-511.)

Gordon, A. L. and Ice StationWeddell Group of Principal Investigators and Chief Scientists. 1993. Weddell Sea exploration from ice station. EOS, 74(11), 121, 124-126.

Harder, M. and H. Fischer. 1999. Sea ice dynamics in the Weddell Sea simulated with an optimized model. F. Geophys. Res., 104(C5), 11,151-11,162.

Harms, S., E. Fahrbach and V. H. Strass. 2001. Sea ice transports in the Weddell Sea. 7. Geophys. Res., $106(\mathrm{C5})$, 9057-9074.

Kottmeier, Ch. and L. Sellmann. 1996. Atmospheric and oceanic forcing of Weddell Sea ice motion. 7. Geophys. Res., 101 (C9), 20,809-20,824.

Kwok, R., A. Schweiger, D. A. Rothrock, S. Pang and C. Kottmeier. 1998. Sea ice motion from satellite passive microwave imagery assessed with ERS SAR and buoy motions. F. Geophys. Res., 103(C4), 8191-8214.

Lange, M. A. and H. Eicken. 1991. The sea ice thickness distribution in the northwestern Weddell Sea. 7. Geophys. Res., 96(C3), 4821-4837.

Lemke, P., ed. 1994. The Expedition Antarktis X/4 of R/V "Polarstern" in 1992. Bremerhaven, Alfred-Wegener-Institut für Polar- und Meeresforschung, Reports on Polar Research 140.

Lemke, P., W. B. Owens and W. D. Hibler, III. 1990. A coupled sea icemixed layer-pycnocline model for the Weddell Sea. 7. Geophys. Res., 95 (C6), 9513-9525.

Limbert, D.W. S., S. J. Morrison, C. B. Sear, P. Wadhams and M. A. Rowe. 1989. Pack-ice motion in the Weddell Sea in relation to weather systems and determination of a Weddell Sea sea-ice budget. Ann. Glaciol., 12, 104-112.

Long, D. G. and M. R. Drinkwater. 1999. Cryosphere applications of NSCAT data. IEEE Trans. Geosci. Remote Sensing, GE-37(3), 1671-1684.

Long, D. G., P. J. Hardin and P.T. Whiting. 1993. Resolution enhancement of spaceborne scatterometer data. IEEE Trans. Geosci. Remote Sensing, GE-31 (3), 700-715.

Maslanik, J. and 6 others. 1998. Summary of ice-motion mapping using passive microwave data. Boulder, CO, National Snow and Ice Data Center. NASA Snow and Ice Distributed Active Archive Center. Polar Data Advisory Group. (Special Publication 8.)

Rott, H., W. Rack, T. Nagler and P. Skvarca. 1998. Climatically induced retreat and collapse of northern Larsen Ice Shelf, Antarctic Peninsula. Ann. Glaciol., 27, 86-92.

Stammerjohn, S., R. Smith, M. R. Drinkwater and X. Liu. 1998. Variability in sea-ice coverage and ice-motion dynamics in the PAL LTER study region west of the Antarctic Peninsula. In IGARSS '98. 18th International Geoscience and Remote Sensing Symposium, 6-10 July 1998, Seattle, Washington. Proceedings. Vol. 3. Piscataway, NJ, Institute of Electrical and Electronics Engineers, 1434-1436.

Strass, V. H. and E. Fahrbach. 1998. Temporal and regional variation of sea ice draft and coverage in the Weddell Sea obtained from upward looking sonars. In Jeffries, M. O., ed. Antarctic sea ice: physical processes, interactions and variability. Washington, DC, American Geophysical Union, 123-139. (Antarctic Research Series 74.)

Thorndike, A. S. and R. Colony. 1982. Sea ice motion in response to geostrophic winds. f. Geophys. Res., 87(C8), 5845-5852.

Timmermann, R., A. Beckmann and H. H. Hellmer. 2001. The role of sea ice in the fresh-water budget of the Weddell Sea, Antarctica. Ann. Glaciol., 33 (see paper in this volume).

Vihma, T., J. Launiainen and J. Uotila. 1996. Weddell Sea ice drift: kinematics and wind forcing. 7. Geophys. Res., 101 (C8), 18,279-18,296.

Wadhams, P., M. A. Lange and S. F. Ackley. 1987. The ice thickness distribution across the Atlantic sector of the Antarctic Ocean in midwinter. F. Geophys. Res., 92(C13), 14,535-14,552.

Warren, B. A. 1981. Deep circulation of the world ocean. In Warren, B. A. and C. Wunsch, eds. Evolution of physical oceanography. Cambridge, MA, MIT Press. 